\title{
The role of the occupational therapist in case management in South Africa
}

\author{
Kreshnee Govender, BOT (UDW), Pg Dip Voc Rehab (UP), MOT (UKZN) \\ Disability and Incapacity Consultant
}

Chantal Christopher, BOT (UDW), MPhil of Group Therapy (UKZN)

Lecturer, Discipline of Occupational Therapy, School of Health Sciences, UKZN

Thanalutchmy Lingah, BOT (UDW), MBA (Wales)

Lecturer, Discipline of Occupational Therapy, School of Health Sciences, UKZN

Introduction: Case Management is fundamental in managed healthcare and has been identified as an established practice delivered by varied health professionals. The aim of the study was to identify the occupational therapist's role and scope of practice in case management in South Africa.

Method: A questionnaire was developed and distributed via Surveymonkey which yielded quantitative and qualitative data.

Results: Occupational therapists are in involved in case manager functions and the extent and intensity of involvement depends on the practice area. More than half the respondents ( $n=43$ i.e. $64 \%$ ) indicated frequent involvement in case management. The majority of respondents indicated that academic preparation in case management would be beneficial at post-graduate level (64\%).

Conclusions: Case management has been implemented by occupational therapists operationally in disability management and as a component of vocational rehabilitation. A high percentage are involved in advocacy for the client, collaboration with the employer in transitioning the client back to work and the coordination of services to enable a work reintegration which are all recognised as case manager functions with an emphasis on occupational performance. Further research is suggested for formalised training in the field to strengthen the occupational therapist as case manager and for the use of a standard of practice in vocational rehabilitation.

Key words: occupational therapy, case management

\section{INTRODUCTION}

Case management is a component of managed healthcare and is defined as a "collaborative process which assesses, plans, implements, coordinates, monitors, and evaluates the options and services required to meet an individual's health needs, using communication and available resources to promote quality, costeffective outcomes"|: 792

Case management originated in the $19^{\text {th }}$ century in the provision of services for impoverished people, followed by coordinated services in the 1970's, targeted towards people with mental health problems and deinstitutionalisation ${ }^{2}$. Case management has been used and applied in various settings such as public health, mental health, social services and the insurance sector; and in the health care setting is generally driven by a nurse case manager ${ }^{3}$. A range of health care professionals are designated as the case manager depending on the setting and the nature of the case.

Occupational therapists are showing an interest in case management and are being challenged to adopt this role in order to succeed in the current health care environment ${ }^{4}$. In this context case management in South Africa is being employed by occupational therapists within different areas of practice such as the insurance sector and health consulting as an approach to manage long term incapacity and disability in the workplace. A need for this service is likely to increase considering the upsurge in disability claims, incapacity and absenteeism in South Africa ${ }^{5}$. Furthermore, the incidence of sick leave in South Africa has risen continuously over the past decade and sickness-related absenteeism has increased four-fold since $2007^{6}$. Case management is further being utilised within the Road Accident Fund to aid motor vehicle accident vic- tims that require long-term care and coordination of healthcare and rehabilitation services. Additionally it has been recognised as a vocational rehabilitation service ${ }^{7}$. Occupational therapists are employing case management as an intervention strategy/approach in their domain of practice but the role of the occupational therapist in case management in South African is however, not defined and their contributions to the field are not well recognised. The purpose of this study was thus to elucidate the role of the occupational therapist in case management in South Africa.

\section{LITERATURE REVIEW}

\section{Evolution of occupational therapy practice roles}

The changes in the health system necessitated a shift in occupational therapy practice from a focus on the medical model to that of occupational performance ${ }^{8}$. The practice of occupational therapy has developed over almost eight decades with a move from the early years of practice within institutional settings to other environments inclusive of healthcare facilities, the community, schools and work sites; this move occurred in response to the changing needs of people with disabilities ${ }^{9}$. Occupational therapy practice roles are emergent in multiple areas with a client-centred approach and emphasis on occupational engagement ${ }^{8}$. Baum \& Law ${ }^{9}$ stated that like other health professionals, occupational therapists are confronted with changing health systems and need to have an understanding of the influencing factors such as legislative frameworks, environmental obstacles, health risk factors and socio-economic conditions.

In South Africa the Labour Relations Act and the Employment Equity Act (that came into effect in 1996 and 1998 respectively) 
presented new opportunities for the occupational therapist in the management of clients with work-related problems due to ill-health or disability ${ }^{10}$. Occupational therapists are well positioned to assess the needs of employees with temporary/permanent impairment or people with disabilities, and to prepare them for work in the open labour market, or for work re-entry following sick absence. Moreover, they are typically the health professional that will be able to make recommendations for reasonable accommodations in the workplace. These services may relate to disability management that the Technical Assistance Guidelines on the Employment of People with Disabilities (TAG) suggests should continue in the workplace to allow for early intervention after the onset of a disability utilising "quality case management and rehabilitation services that reflect an organisation's commitment to continued employment of those experiencing functional work limitations" |1:46.

\section{The role of a case manager}

The Case Management Society of America (CMSA) ${ }^{12}$ recognises case managers as skilled professionals that are key contributors in the care coordination team to allow for access to quality healthcare; and aids in the transition of care to the next level. Correspondingly the Case Manager Association of South Africa (CMASA) identifies the case manager as a clinical practitioner specialist involved in the coordination of care, resulting in quality care and cost containment ${ }^{13}$. Furthermore, in fulfilling their functions, case managers are involved in comprehensive assessments to develop a care plan where the planning is done in conjunction with the client, family, specialists, healthcare providers and payer to facilitate maximum response and cost effective outcomes ${ }^{12}$.

Case managers are responsible for collaborating and negotiating with the relevant stakeholders to facilitate follow-through with the treatment plan and at the same time ensuring cost effectiveness'. A client-centred approach is adopted which entails empowering and educating the client, a step which is essential to meet the goals set ${ }^{12}$. Additionally client advocacy has been identified as a vital attribute in the achievement of positive outcomes ${ }^{4,12}$. In performing these functions, case managers may work internally such as in a hospital setting where there is direct contact with the client or externally where they are not necessarily involved in client care but essentially manage cases by coordinating aspects of the care for an insurance company or employer ${ }^{14}$. The Case Manager Association of South Africa recognises that case management is also utilised in areas other than the hospital, managed health care organisations and medical health schemes and is currently used in vocational or return-to-work programmes where injury or illness impacts on the employee's work ability and retention at work ${ }^{13}$.

\section{The occupational therapist as case manager}

International literature reveals that occupational therapists are seeking to define their role in case management amidst changing healthcare environments and in response to the needs of the client which includes access to effective, quality, timely and cost effective services $^{4,9,10}$

Dufrense ${ }^{15}$ stated that the American Occupational Therapy Association has affirmed that the occupational therapist can in fact perform the role of a case manager and that there will be benefit from the occupational therapist as case manager when disability affects performance in activities of daily living.

Baldwin and Fisher ${ }^{16}$ found that the functions of a case manager and that of an occupational therapist compares favourably following a comparison of the occupational therapist's functions to that of a case manager as outlined by the Case Management Society of America Standards of Care for a case manager. The salient features of effective case management include the identification of the client's needs, the provision of appropriate medical treatment that includes mental and physical rehabilitation, the provision of daily living support and the provision of vocational training or re-training ${ }^{17}$. These characteristics are similar to those of an occupational therapy service in that a holistic view is adopted by occupational therapists with emphasis on functional ability instead of treating illness, and as such, independence and facilitating community integration are promoted.

There is limited South African literature on the role of the occupational therapist in case management. Byrne ${ }^{18}$ stated that occupational therapists in the South African insurance industry may perform similar functions to that of a case manager whereas, in a paper on the Professional Competencies in Vocational Rehabilitation, Buys ${ }^{7}$ referred to case management as a vocational rehabilitation service. It therefore appears that in South Africa, occupational therapists are involved in case management either internally for example in the provision of a vocational rehabilitation service and externally within the insurance sector. Notwithstanding, given the scant literature in the South African context, it is necessary to identify the occupational therapist's role and scope in case management and to acknowledge the contributions made to the field.

\section{METHODOLOGY}

\section{Study method}

At commencement of this research there was no available data collection tool. As such a questionnaire was developed by the researcher as the data collection method in order to gather both quantitative and qualitative information to answer the research questions i.e. what is the role of the South African occupational therapist in case management and does the South African occupational therapist's scope of practice and functions speak to that of a case manager?

The questionnaire design was informed by literature on case management and case manager functions. In construction of the questionnaire, the type of information, questions, responses, validity and reliability were taken into consideration. The quantitative dominant questionnaire also elicited qualitative data which were obtained using open ended questions to answer the objectives of the study ${ }^{19}$. The objectives were: identification of the effectiveness of case management; description of the challenges or practice difficulties by occupational therapists in case management; and a description of the skills-base and knowledge of occupational therapists relevant to case management.

\section{Ethical clearance}

Ethical clearance (HSS/0 I34/0 I 6M) was obtained from the Humanities \& Social Sciences Research Ethics Committee of the University of KwaZulu-Natal.

\section{Data Collection}

Given the researcher's knowledge of the use of case management by occupational therapists in private practice, in health consulting, the Road Accident Fund (RAF) and the insurance sector, these areas were targeted within this study. Purposive sampling was therefore applied which involves using a specific target group given their knowledge and experience in the field ${ }^{20}$. The participants who met the inclusion criteria i.e. qualified occupational therapists working in the private sector, those specialising in vocational rehabilitation in the private sector; working in health consulting and insurance sectors; occupational therapists involved in medico-legal work and work with RAF, were considered to be most suitably placed to provide the required information. A list of occupational therapists in private practice (a total of I I 2) was obtained from the researcher's work area in health consulting and included those that work with adults and paediatrics. This was inclusive of occupational therapists that provide services to RAF such as medico-legal assessments and rehabilitation.

The questionnaire was distributed to a total of I 80 occupational therapists that met the inclusion criteria excluding those that work for RAF, as permission to distribute the survey was obtained after the data collection period. Notwithstanding, the survey was distributed to occupational therapists that are in private practice and that are directly involved in service provision to RAF. As displayed 
Table I: Sample selection

\begin{tabular}{|l|c|}
\hline Area of work & Number of occupational Therapists \\
\hline Private practice & 112 \\
\hline Insurance & 47 \\
\hline Health consulting & 21 \\
\hline Total & 180 \\
\hline
\end{tabular}

in Table I above, the target population comprised I I 2 occupational therapists in private practice, 47 in the insurance industry, and 21 in health consulting.

Occupational therapists working in the public sector have been excluded from this study as case management within these institutions typically forms part of managed health care fulfilled by a nurse case manager ${ }^{21}$. Occupational therapists in community service or those that have just qualified were excluded from the study as case management has been identified as a specialised area of practice ${ }^{16}$. The data were collected via Surveymonkey. For the closed-ended questions, a five point Likert Scale was used with weights attached to each chosen answer enabling Surveymonkey to calculate the mean for each response for an analysis of the results section.

A pilot study was conducted with 10 occupational therapists to determine content validity and the time taken to complete the questionnaire. Refinement of the questionnaire was done on receipt of feedback from the pilot sample.

Reliability of the instrument was considered having designed a questionnaire that was simple to complete with questions that were clear and self-explanatory. In addition, the instrument was administered in a standardised method as per a pre-set procedure using Surveymonkey ${ }^{22}$. It was also assumed that the use of an on-line data collection tool would facilitate better response rates considering the ease in which the questionnaire can be accessed and completed via Surveymonkey ${ }^{23}$.

Reliability in terms of the qualitative data was addressed using regular comparison of the data against the codes and by making notes on the codes and definitions to ensure that there is no shift in the meaning of the codes during the coding process ${ }^{19}$.

In order to ensure content validity, a thorough review of the literature preceded the design of the data collection instrument. The questionnaire was designed in relation to the objectives of the study and with reference to the literature. Moreover the questionnaire was pilot-tested to determine content validity which assisted in enhancement of the instrument.

Validity of the qualitative data was addressed using the following strategies:

* rich, thick description was used to convey the findings under the results which ensured that many perspectives were provided about the themes ${ }^{24}$;

* clarification of bias the researcher brings to the study. The researcher's interpretation of the findings and the thematic analysis were based on the researcher's experience in the field and the use of case management in practice ${ }^{19}$;

* code-recode (which entailed coding the data twice over a two week period) was performed during which the codes were compared to determine whether there were similarities or differences. After utilisation of the code-recode strategy it was found that the results were in agreement which enhanced the dependability of the qualitative data. This further improved presentation of the narratives from the participants ${ }^{25}$;

* trustworthiness of the qualitative data which was obtained consistently by the administration of a questionnaire via Surveymonkey in such a manner that the findings are representative of plausible information ${ }^{25}$.

\section{Data analysis}

The data were exported from Surveymonkey to an Excel spreadsheet for analysis with assistance from a statistician from the
Department of Biostatistics at the University of KwaZulu-Natal. A quantitative analysis was employed by deriving the means of the closed-ended response data. The mean represented the average of the responses that ranged from one to five on a five-point Likert scale. A bivariate analysis (using the Fisher's Exact Test) was employed to explore the relationship between two variables; to denote if there were non-random associations between two categorical variables and to determine the significance of the associations. In this study the test was used to compare categorical data with two nominal variables. The test was also suitable as it is recommended for sample sizes that are less than $1000^{26}$. Statistical significance results of the quantitative data was applied through the use of descriptive statistics ${ }^{27}$.

Thematic analysis was conducted for the open-ended questions which entailed coding of the qualitative data in order to identify and distinguish primary and secondary themes. Firstly the thematic analysis entailed export of the responses from Surveymonkey to an Excel spreadsheet. This was followed by a review of the information, grouping of similar diverse responses, linkage of sub-themes, and finally, themes were derived ${ }^{24}$.

\section{RESULTS}

\section{Response rate}

Of the total population of 180 there were 77 respondents, reflecting a $42 \%$ response rate. Acceptable response rates vary depending on how the survey was administered. On average a $30 \%$ response rate for surveys administered online is considered to be acceptable ${ }^{23}$. A sampling distribution of the mean that is very close to a normal distribution will generally result with a sample size of 30 or more ${ }^{28}$.

\section{Demographic profile}

The majority of respondents (7I\%) had I 0 or more years of experience as occupational therapists. A small percentage of respondents (5\%) had I-3 years of experience as occupational therapists suggesting that the sample comprised a reasonably experienced group of occupational therapists.

\section{Domains of practice of respondents}

Of the 77 occupational therapists, $32(47 \%)$ had no qualifications after undergraduate training, 12 or $16 \%$ had a Post-graduate Diploma in Vocational Rehabilitation, whilst II (I4\%) had Master's Degrees, two of which were Master's Degrees in Occupational Therapy. Certification in functional capacity evaluation courses such as Workwell Systems and Ergoscience was obtained by four (5\%) of the sample. Almost half (34) of the respondents (44\%) belonged to the professional organisation OTASA (Occupational Therapy Association of South Africa). Only one respondent was a member of the Case Manager Association of South Africa. Most of the respondents practiced occupational therapy in the Gauteng region (49\% or 36 ) followed by KwaZulu-Natal (I8\% or 14) and the Western Cape (I7\% or 13). The geographical distribution correlates to the area of practice as the majority of the respondents were based within the insurance sector $(61 \%$ or 47$)$ that is predominantly located in the Gauteng region. A high percentage of respondents were also from private practice $(53 \%$ or $4 \mathrm{I})$. In responding to the question regarding the area of practice, respondents could select more than one practice area. RAF constituted 19\% of the practice areas (I 5 respondents). These occupational therapists may not be employed by the Fund but provide services directly to RAF. Health consulting ranked fourth ( $10 \%$ or eight respondents) in terms of top areas of practice.

Eight percent (six) of the respondents worked in hospitals/ rehabilitation hospitals. The majority of these respondents (83\%) or five of the six respondents also worked in other areas i.e. in private practice, in the insurance sector and with Workmen's Compensation cases. Only one indicated that a hospital was their exclusive area of work.

In responding to the question regarding the domain of practice, respondents could select more than one domain. As depicted in 
Figure I (below), disability management ranked the highest $(65 \%$ or 50 respondents) as a domain of practice which is expected considering that $61 \%$ of the respondents are from the insurance sector. This is followed by vocational rehabilitation ( $41 \%$ or 32 respondents) which links to the percentage of occupational therapists that work in private practice. Of the 42 occupational therapists in private practice $60 \%$ (Figure 2 opposite) indicated vocational rehabilitation as a domain of practice which suggests that this is a prevalent field amongst this sample group within the private practice sphere. Of the 77 respondents a similar numbers practiced in the field/domains of physical health $38 \%(30)$, medico-legal work $38 \%$ (30) and absenteeism and incapacity management 37\% (29).

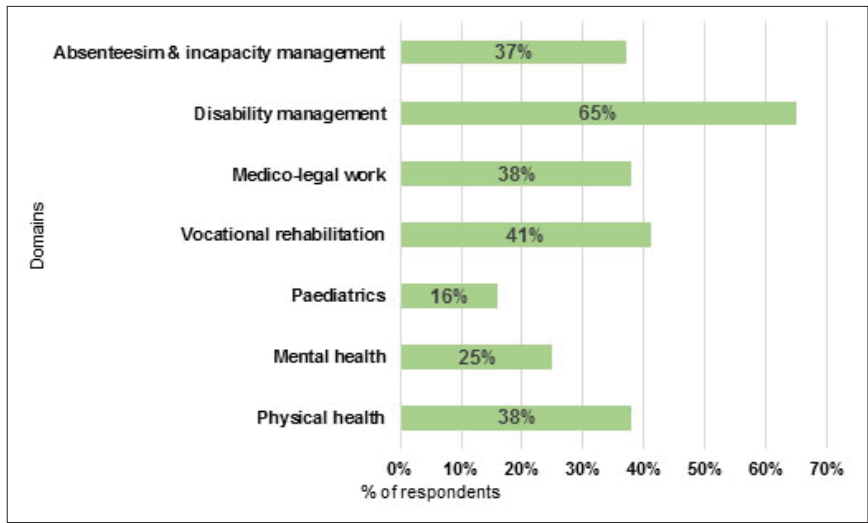

Figure I: Domains of practice of respondents

\section{Involvement in Case Manager Functions}

Results indicate that the respondents were intervening with functions that have been documented as case manager role functions as per the Case Management Society of America's Standard of Practice for Case Management ${ }^{12}$.

As depicted in Table I/ below a high percentage of occupational therapists are involved in advocating for both the client and the payer/referral source to facilitate positive outcomes (mean $=4.2 \mathrm{I}$ ).

Advocacy is typically an established skill of occupational therapists in addressing clients' needs holistically through collaborative communication, client support and empowerment to enable an improvement in their functional levels. Most of these respondents are from the insurance sector $(89 \%$ or 39$)$ which suggests that

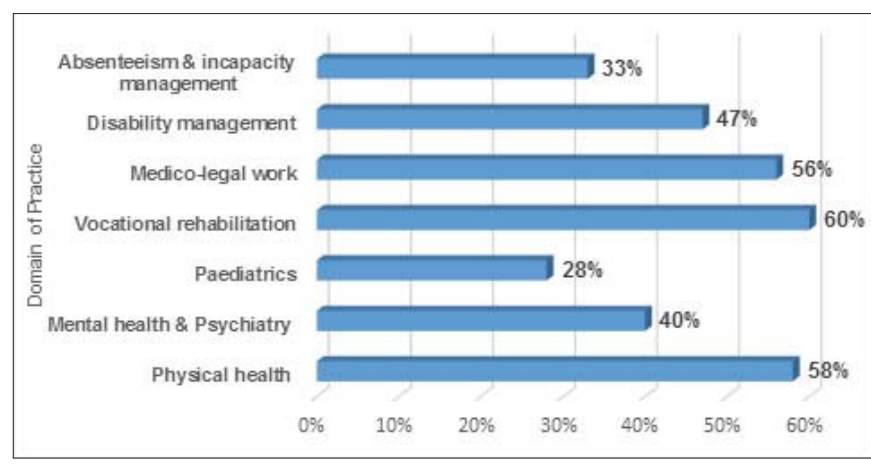

Figure 2: Private occupational therapists' domains of practice

this function is directly associated with disability claims management in the field. More specifically respondents indicated frequent involvement in advocating for on-going medical and/or rehabilitation interventions as shown in Table III below which is in keeping with the management of disability claims by an occupational therapist working within group life insurance companies where recommendations are made for rehabilitation and or re-skilling/training to aid in a work re-entry ${ }^{7}$.

Table III: Frequency of involvement in case manager role functions

\begin{tabular}{|l|c|}
\hline Interventions & Mean \\
\hline $\begin{array}{l}\text { Coordination of complicated treatment regimen in } \\
\text { rehabilitation setting }\end{array}$ & 2.18 \\
\hline $\begin{array}{l}\text { Coordination \& accessing services to assist in the } \\
\text { management of the clients' reintegration in the work } \\
\text { environment }\end{array}$ & 3.50 \\
\hline $\begin{array}{l}\text { Liaison with the relevant role player for rehabilitation or } \\
\text { training }\end{array}$ & 3.22 \\
\hline $\begin{array}{l}\text { Liaison with the employer to aid in the employee's } \\
\text { transition back to work }\end{array}$ & 3.66 \\
\hline $\begin{array}{l}\text { Work site visits to assess the requirements \& needs of the } \\
\text { employee and employer }\end{array}$ & 3.37 \\
\hline $\begin{array}{l}\text { Advocate for on-going medical \& or rehabilitation } \\
\text { interventions }\end{array}$ & 3.70 \\
\hline
\end{tabular}

Table II: Percentage of involvement in case manager functions

\begin{tabular}{|c|c|c|c|c|c|c|c|}
\hline Case Manager Role Functions & $\begin{array}{l}\text { Hospital/ } \\
\text { rehabilitation } \\
\text { hospital }\end{array}$ & $\begin{array}{l}\text { Private } \\
\text { practice }\end{array}$ & Insurance & $\begin{array}{l}\text { Health } \\
\text { consulting }\end{array}$ & RAF & $\begin{array}{l}\text { Workmen's } \\
\text { comp }\end{array}$ & $\begin{array}{l}\text { Rating } \\
\text { Average }\end{array}$ \\
\hline Total no. of 'Yes' responses & $n=6$ & $n=36$ & $n=44$ & $n=8$ & $n=13$ & $n=6$ & \\
\hline $\begin{array}{l}\text { Comprehensive evaluation to develop a care } \\
\text { plan }\end{array}$ & $4(67 \%)$ & $30(83 \%)$ & $25(57 \%)$ & $6(75 \%)$ & $9(69 \%)$ & $5(83 \%)$ & 3.66 \\
\hline $\begin{array}{l}\text { Plan with the client \& service provider/referral } \\
\text { source to ensure optimisation of treatment }\end{array}$ & $4(67 \%)$ & $27(75 \%)$ & $31(70 \%)$ & $7(88 \%)$ & II (85\%) & $5(83 \%)$ & 3.76 \\
\hline $\begin{array}{l}\text { Facilitate communication \& coordination } \\
\text { between role players to minimise } \\
\text { fragmentation in services }\end{array}$ & $3(50 \%)$ & $21(58 \%)$ & $31(70 \%)$ & 7 (88\%) & 10 (77\%) & $4(67 \%)$ & 3.66 \\
\hline $\begin{array}{l}\text { Educate/empower client/health care team } \\
\text { on treatment options/community resources/ } \\
\text { benefits }\end{array}$ & $4(67 \%)$ & $27(75 \%)$ & 27 (6।\%) & $6(75 \%)$ & $9(69 \%)$ & $5(83 \%)$ & 3.67 \\
\hline $\begin{array}{l}\text { Encourage appropriate use of health care } \\
\text { services/benefits to improve quality of care \& } \\
\text { maintain cost effectiveness }\end{array}$ & $5(83 \%)$ & $28(78 \%)$ & 35 (80\%) & $6(75 \%)$ & 10 (77\%) & $5(83 \%)$ & 3.79 \\
\hline $\begin{array}{l}\text { Assist in client transition back into the home/ } \\
\text { community/work environment }\end{array}$ & $5(83 \%)$ & $26(72 \%)$ & 35 (80\%) & 7 (88\%) & $9(69 \%)$ & $5(83 \%)$ & 3.96 \\
\hline $\begin{array}{l}\text { Advocate for client \& payer/referral source to } \\
\text { facilitate positive outcomes }\end{array}$ & $5(83 \%)$ & $31(86 \%)$ & 39 (89\%) & $6(75 \%)$ & II (85\%) & $5(83 \%)$ & 4.21 \\
\hline
\end{tabular}


Encouraging the appropriate use of health care services/benefits to improve quality of care and maintain cost effectiveness $($ mean $=3.79)$ is indicative of an integrated, client-centred approach that correlates to occupational therapy practice. The majority of these respondents within their individual practice areas are from hospitals ( $83 \%$ or five out of six respondents) and Workmen's Compensation ( $83 \%$ or five out of six respondents) which relates to managed health care and further illustrates the occupational therapists' role as a case manager. In addition, there is some consensus for involvement in case manager functions such as planning with the client and service provider/referral source to ensure optimisation of treatment (mean $=3.76$ ) and assistance in transitioning the client back into the home/community/work environment (mean=3.96). Table II (page 15) indicates that a high number of respondents in relation to the practice area that are involved in planning with the client and service provider or referral source are also from health consulting $(75 \%)$ areas of practice and $\operatorname{RAF}(85 \%)$. This is associated with brokerage functions within health consulting and facilitation of access to medical and rehabilitative care for the RAF.

Transitioning of a client to the next level of care corresponds strongly to the occupational therapist's capacity in community and work reintegration and it is noteworthy that the highest proportion of respondents that were involved in transition of the client into the community or work environment are from health consulting ( $88 \%$ or seven out of eight respondents).

\section{Level of involvement in comprehensive evaluations to develop a care plan}

The case management process includes an evaluation to develop a care plan ${ }^{14}$. The proportion of respondents that were involved in comprehensive evaluation of the client to develop a care plan was

Table IV: Comparison of the level of involvement in comprehensive evaluations to develop a care plan per practice area

\begin{tabular}{|l|c|c|c|}
\hline Areas of work & Mean & $\begin{array}{c}\text { Level of } \\
\text { significance }\end{array}$ & p-value \\
\hline Private practice & 4.19 & $*$ & $<0.00$ I \\
\hline Workmen's Comp & 4.33 & & 0.4 \\
\hline Health consultancy /broker & 4.42 & & 0.7 \\
\hline RAF & 3.76 & & 0.8 \\
\hline Hospitals & 4.2 & & 0.9 \\
\hline Insurance sector & 3.59 & & 0.2 \\
\hline $\begin{array}{l}\text { * Significant at the I0\% level } \\
\text { ** Significant at the 5\% level }\end{array}$ & & \\
\hline
\end{tabular}

significantly greater $(\mathrm{p} \leq 0.00 \mathrm{I})$ in private practice as reflected in Table IV below. Fewer occupational therapists involved in this area of intervention were from the insurance industry (mean=3.59). This suggests that occupational therapists in private practice are more involved in comprehensive evaluations compared to those in other areas and are particularly receiving referrals for evaluations from insurance, health consultancy and RAF so that a plan of care for the client can be derived.

These results reveal that occupational therapists are therefore not only planning and directing therapy programmes but are assuming case manager functions where there is linkage and involvement of the team.

In order to identify the specific areas of intervention related to case management, participants had to indicate the frequency of involvement in interventions that are relative to case manager functions. Advocacy for on-going medical and/or rehabilitation interventions, liaison with the employer to aid in the employee's transition back to work (mean $=3.66$ ) and coordination and accessing services to assist in the management of the clients' reintegration in the work environment (mean $=3.50$ ) were found to be common role functions (see Table III, page I5). Occupational therapists were further involved in work-site visits to assess the requirements and needs of the employee and employer. Occupational therapists were rarely (mean $=2.18$ ) involved in the coordination of complicated treatment regimens in rehabilitation settings which is expected as in South Africa this function is commonly performed by a nurse case manager within this particular area of practice.

Frequency of involvement in case manager role functions per area of practice

Frequent involvement by respondents from the insurance sector ( $73 \%$ or 32 of 44 respondents) in the coordination and access of services to assist in the management of the clients' reintegration in the work environment yielding a p value of 0.02 (Table $V$ below) highlighted the relationship between this function and the area of practice. This is reflective of participation in coordination of services, a key case manager function with the aim of retaining the client at work despite the effects of illness or a disabling medical condition.

Occupational therapists in private practice were not involved in monitoring progress and support from service providers whilst the $p$ value of 0.01 (Table $V$ ) for insurance indicates that these respondents were more frequently involved in this function documented as part of the case management standard of practice ${ }^{14}$ Occupational therapists in private practice were commonly involved in work-site visits as indicated in table $V$ above $(p$ value $=0.00 \mathrm{I}$ ). Moreover, $91 \%$ of respondents that worked in the insurance sector were making referrals to occupational therapists in private practice for work-site visits (Figure 3, page 17). This may also be associated with the case manager function of transitioning the client back into the

Table V: Frequency of involvement in case manager role functions per area of practice

\begin{tabular}{|c|c|c|c|c|c|c|}
\hline Area of practice & & Private & & & nsurance & \\
\hline Response & Yes & No & P value & Yes & No & P value \\
\hline Interventions & $\mathbf{n}=36$ & $\mathbf{n}=\mathbf{3} \mathbf{I}$ & & $n=44$ & $n=23$ & \\
\hline Assess in the acute setting & $13(36 \%)$ & $2(5 \%)$ & 0.007 & $8(18 \%)$ & $7(40 \%)$ & 0.4 \\
\hline Coordination of assessments \& referrals & $18(50 \%)$ & $18(58 \%)$ & 0.6 & $25(57 \%)$ & II (48\%) & 0.6 \\
\hline Coordinates regimen in a rehabilitation setting & $10(28 \%)$ & $4(13 \%)$ & 0.2 & $9(20 \%)$ & $5(22 \%)$ & 0.9 \\
\hline Coordinates $\&$ accesses community services & $27(75 \%)$ & $17(54 \%)$ & 0.1 & $27(61 \%)$ & $17(74 \%)$ & 0.4 \\
\hline Coordinates \& accesses services for work reintegration & $20(57 \%)$ & $21(68 \%)$ & 0.5 & $32(73 \%)$ & $9(4 \mid \%)$ & 0.02 \\
\hline Negotiate the service within the benefit program & $15(42 \%)$ & $19(61 \%)$ & 0.1 & $26(59 \%)$ & $8(35 \%)$ & 0.08 \\
\hline Monitoring progress \& support from service providers & $13(36 \%)$ & $23(74 \%)$ & 0.003 & $29(66 \%)$ & $7(30 \%)$ & 0.01 \\
\hline Liaison with role player for rehab \& training & $8(22 \%)$ & $3(10 \%)$ & 0.2 & $7(16 \%)$ & $4(17 \%)$ & 0.9 \\
\hline Work site visits to assess needs of employer \& employee & $27(75 \%)$ & II (35\%) & 0.001 & $25(57 \%)$ & $13(57 \%)$ & 0.9 \\
\hline Advocate ongoing medical \& rehabilitation services & $27(75 \%)$ & $24(77 \%)$ & 0.9 & $34(77 \%)$ & 17 (74\%) & 0.8 \\
\hline
\end{tabular}


work environment. Of the 33 respondents that received referrals for work-site visits, $63 \%$ or 21 were from private practice. This usually precedes or is associated with the function of transitioning the client to the work environment which further demonstrates the role of the occupational therapist as case manager.

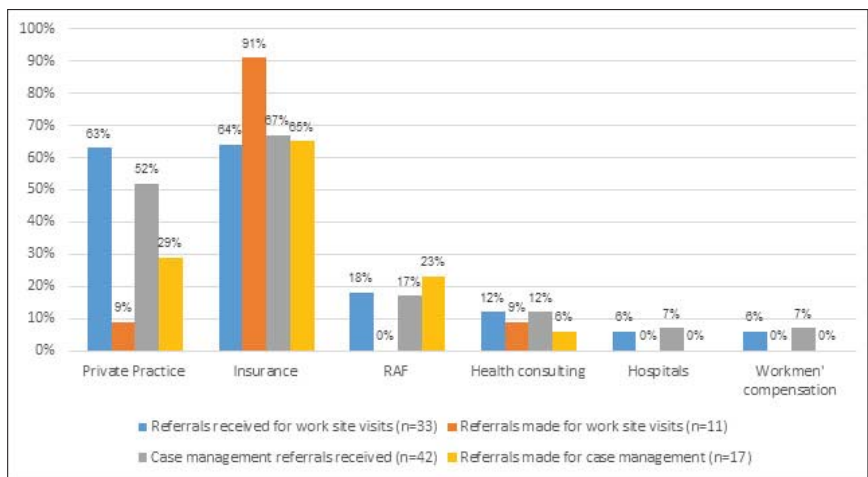

Figure 3: Referrals for work site visits and case management per area of practice

\section{Service involvement}

The respondents had to rate their involvement in services on a five-point scale, ranging from not at all to very frequently. Certain respondents indicated multiple areas of practice for e.g. insurance and private practice and are thus involved in a particular service in more than one area. A total of 67 respondents to the question, mostly from private practice and the insurance sector indicated frequent involvement in disability management $(63 \%$ or 42$)$, case management $(64 \%$ or 43$)$ and functional capacity evaluations $(55 \%$ or 37 ), (Figure 4, below). Case management thus appeared as the foremost service that respondents are involved in.

Figure 4: Percentage of service involvement

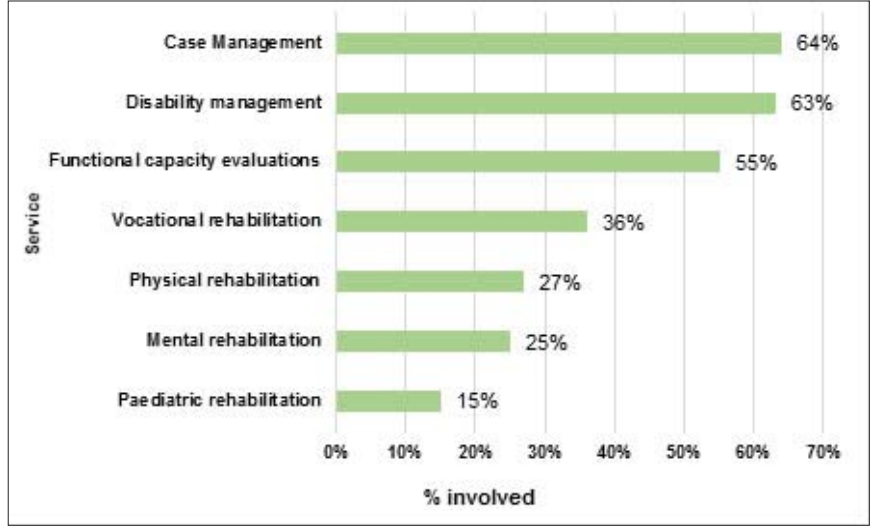

Figure 5: Percentage of service involvement by respondents in insurance and private practice

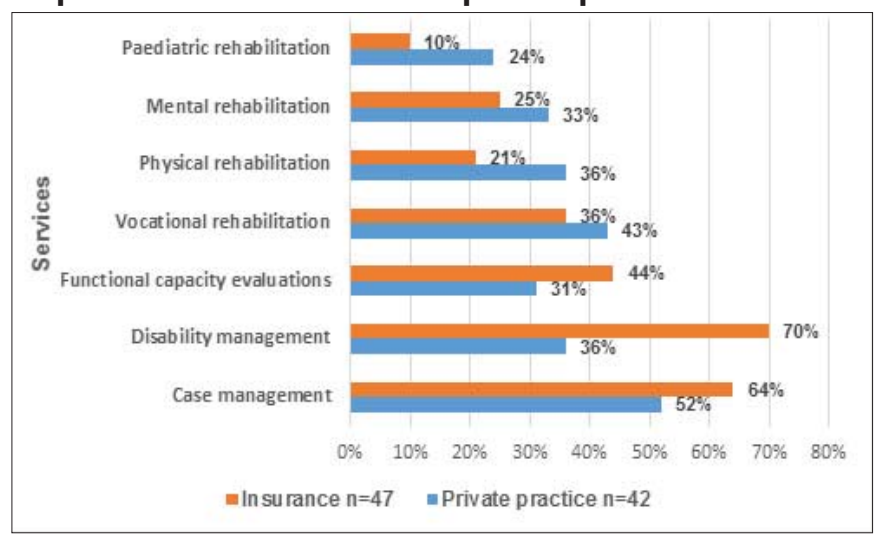

As depicted in Figure 5 below disability management reflected largely as a role function of occupational therapists in the insurance sector $(70 \%$ or 33$)$ which relates to disability claims management.

Of the 47 respondents within the insurance sector 30 or $64 \%$ were frequently involved in case management, whilst $52 \%$ or 22 of the 42 respondents in private practice were frequently involved in this service (Figure 5). Case management referrals were received predominantly by respondents from the insurance sector $(67 \%$ or 28$)$ and private practice $(52 \%$ or 22$)$ as shown in Figure 3. Occupational therapists working within the insurance sector (65\% or II) also referred to other therapists for case management as depicted in Figure 3. A smaller proportion of occupational therapists were frequently involved in physical rehabilitation ( $27 \%$ or 21 ) and mental rehabilitation ( $25 \%$ or 19$)$ compared to other domains such as functional capacity evaluations which is of interest (Figure 4). All occupational therapists that work with RAF were involved in medico-legal assessments and all occupational therapists from health consulting indicated involvement in absenteeism and incapacity management suggestive of main domains of practice. As displayed in Figure 4 there was frequent involvement in vocational rehabilitation $(36 \%$ or 28) most of which are from insurance and private practice. From these findings it can be deduced that this group of occupational therapists were more involved in service provision in the fields of disability management, case management $(64 \%$ or 49$)$ and functional capacity evaluations at varying degrees (depending on the setting) relative to other fields such as physical and mental rehabilitation which is central to their scope of practice.

\section{Years of experience and academic preparation for case management}

In general the sample comprised more experienced occupational therapists. Of the 77 respondents 52 (68\%) responded to the question about the years of experience they had in case management. The results indicated variable years of experience most of which ( $25 \%$ or 1 3 ) have I-3 years' experience in the field (Figure 6). Of the II (2I\%) respondents who indicated 10 years or more experience, $18 \%$ or two worked in private practice and one in the insurance sector. The I I occupational therapists with less than one year of experience in case management worked in private practice ( $18 \%$ or two) and the insurance industry (one).

\section{Figure 6: Years of experience in case management}

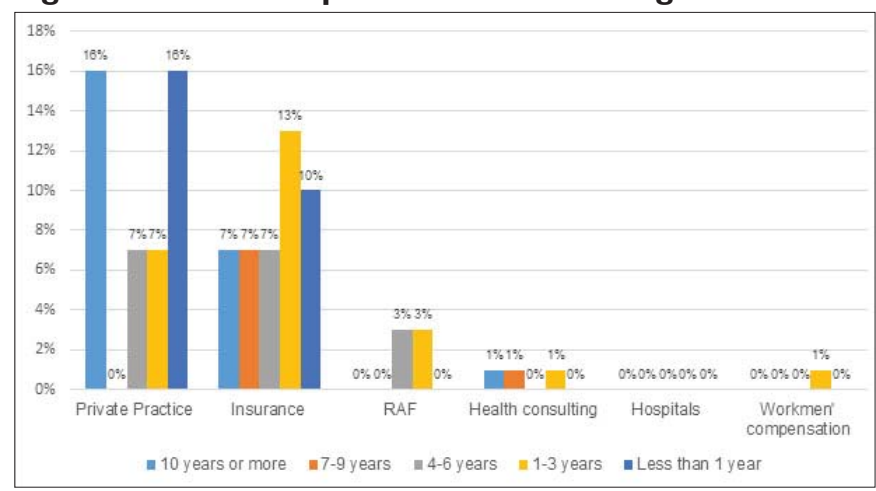

Of the 77 respondents, 49 responded to the question on academic preparation in case management. Thirty four percent or 17 respondents indicated that no or little training and academic preparation had been received in case management; $24 \%$ or 12 had learnt through experience whilst $20 \%$ or 10 indicated that training was received through a Postgraduate Diploma in Vocational Rehabilitation, while one respondent indicated that he/she is the provider of training in case management.

Of the 77 respondents, 53 responded to the question on the benefits of training in case management. All 53 respondents indicated that occupational therapists would benefit from training in this 
domain of practice. Occupational therapists suggested that there would be benefit at a post-graduate level $(64 \%$ or 34$)$ as well as in-house training ( $52 \%$ or 28 ). The minority ( $48 \%$ or 25$)$ indicated that there would be benefit from training in case management at an undergraduate level. Although there are mixed opinions about the level at which it should occur, all respondents indicated that educational preparation in case management would be beneficial. International literature supports the need for better training ${ }^{4,15 \& 17}$ whilst in a South African research paper, case management has been documented as a professional competency in vocational rehabilitation ${ }^{7}$.

\section{DISCUSSION}

The results revealed that occupational therapists are involved in areas of intervention that are recognisable as case manager functions at varying degrees depending on the area of practice. The role of the occupational therapist in case management is exemplified by their frequent involvement in client advocacy and more specifically advocating for ongoing services (medical/rehabilitation); collaboration with the employer to aid in the transition back to work and the coordination of services to facilitate the client's work reintegration all of which are identifiable as case manager functions with a focus on occupational performance. Collaboration and coordination of services have been recognised as case management and this is referred to as a 'vocational rehabilitation service'7.

The findings indicate that most occupational therapists are involved in the case manager function of advocating for both the client and the payer/referral source with the majority being from the insurance sector - this may be expected as advocacy is directly associated with disability claims management in the field. Within the insurance sector a key performance area of the therapist is disability claims management which also entails advocating for the client via recommendations and advice for further management and rehabilitation to facilitate return to work ${ }^{18}$. A high percentage of occupational therapists agreed that there is involvement in encouraging the appropriate use of health care services/benefits to improve quality of care and maintain cost effectiveness (most of which are from hospital practice areas and Workmen's Compensation). This is typically in keeping with the function of case managers in hospital settings. Furthermore there is a level of agreement regarding involvement in planning with the client and the service provider/ referral source to ensure optimisation of treatment and assistance in transitioning the client back into the home/community/work environment and further illustrates participation in a fundamental case manager function documented as a component of the standard in case management ${ }^{14}$.

The highest proportion of occupational therapists involved in comprehensive evaluation to develop a care plan are from private practice. This is expected as a detailed evaluation would usually precede the treatment or other interventions or it may be the reason for referral to the occupational therapist. It is interesting to note that a higher proportion of occupational therapists are more frequently involved in functional capacity evaluations rather than physical and mental rehabilitation. It is expected that the smallest proportion of occupational therapists involved in this area of intervention are from insurance as they are not involved in clinical work which includes comprehensive evaluation. Occupational therapists working in the insurance industry are however, more involved in advocating to facilitate positive outcomes, transitioning the client into the community or work environment and encouraging appropriate use of healthcare. This relates to the key functions performed by occupational therapists in the life insurance industry as identified by Byrne ${ }^{18}$ i.e. disability claims assessment/management, consultation with the employer and making recommendations for rehabilitation; motivating stakeholders on benefits and for referring claimants to service providers.

Occupational therapists in private practice and the insurance industry are more frequently involved in specific case manager functions such as the coordination and accessing of services to assist in the management of the clients' work reintegration. This relates to one of the key functions of the occupational therapists in the insurance industry, which is to manage claims to determine the extent of occupational incapacity/disability and to facilitate a return to work. Occupational therapists from the insurance industry are also referring to other occupational therapists for functional capacity evaluation, independent evaluations and vocational rehabilitation which in turn, are related to their involvement in case manager functions such as coordination of assessments and referrals. Moreover, there is regular participation in monitoring progress and support from service providers which is further related to their role functions in disability claims management where services such as specialist evaluation and reports are usually outsourced in order to gather additional and updated information on the claimant's medical condition/progress and the impact thereof on work ability. A noteworthy finding is that occupational therapists within insurance are in fact utilising case management as an intervention in managing disability claims: $67 \%$ or 28 respondents indicated receipt of referrals for case management but are also referring to external occupational therapists for case management considering that $65 \%$ or I I respondents indicated that referrals are made specifically for this service. In this context given the increase in disability claims prevalence the demand for case management is likely to expand ${ }^{18,29-30}$.

As a domain of practice $37 \%$ or 29 respondents indicated absenteeism and incapacity management and of the 43 occupational therapists that indicated frequent involvement in case management $14 \%$ or six respondents are from the health consultancy field. Case management therefore appears to be utilised as part of an early intervention approach once there has been an extended period of absence from work or a high rate of absence due to illness (where the service entails comprehensive assessment to determine a care plan and coordinating and monitoring client care to prevent long term absenteeism thereby contributing to cost containment).

The research results indicate findings that are consistent with published international literature on occupational therapists as case managers ${ }^{4,15,16,31}$. These findings suggest that occupational therapists in South Africa are performing case management as an operational component of disability management as suggested by the Technical Assistance Guidelines of the Employment of People with Disabilities " . It is also evident that case management is utilised in vocational rehabilitation. Case management is a specialised area of practice ${ }^{|4,2|}$ and training in the field is not overt in occupational therapy training programmes. Even though most occupational therapists have post-graduate qualifications and training with 10 or more years of experience, the therapists in this study all indicated that there would be benefit from training in case management at both under- and post-graduate levels.

\section{LIMITATIONS}

The response rate of $42 \%$ is regarded as low and is reflective of sample bias despite the number of occupational therapists targeted for participation and use of repeat email reminders. This low response rate may be due to various reasons such as non-involvement in case management or insufficient knowledge on this domain of practice.

\section{CONCLUSION}

This research study was new in the South African context; and aimed to identify the occupational therapist's role and scope of practice in case management in South Africa. The study reveals that occupational therapists in South Africa are involved in case manager functions and are implementing case management as a strategy or approach to manage incapacity due to ill-health and disability in the workplace. In keeping with international literature, the study affirms that occupational therapists are offering unique skills to the field with their ability to address the clients' needs holistically with an emphasis on improving and maintaining their abilities to engage in purposeful activity. They are natural advocates for their clients 
and results of the study indicate participation in aspects of client care that are recognised as case manager functions. Involvement in case management functions vary and range from brokerage functions by therapists working in insurance and health consultancy to more comprehensive and direct care by therapists in private practice. Occupational therapists in South Africa that are positioned in various settings viz. insurance, private practice, health consulting, and Workmen's Compensation, have indicated involvement in case management and this study confirmed the utilisation of this intervention in vocational rehabilitation and as an element of disability management. Occupational therapists indicated that there would be benefit from training specific to case management at under and post -graduate levels. Further research may therefore be necessary regarding the inclusion thereof in the under-graduate and or post-graduate curricula. Given their current contributions to the field, occupational therapists face the challenge of expanding their knowledge in case management and in promoting their skills to allow for relevant utilisation of this approach with an emphasis on early intervention. Considering the use of case management with a focus on occupational performance - further research may be necessary to establish a standard of practice for application in vocational rehabilitation.

\section{REFERENCES}

I. Kongstvedt PR. The managed health care handbook. Jones \& Bartlett Learning, 200I.

2. Linz MH, McAnally PL, Wieck CA. Case management: Historical, current, \& future perspectives. Brookline Books, 1989.

3. Cohen EL, Cesta TG. Nursing case management: From essentials to advanced practice applications. Elsevier Health Sciences, 2005.

4. Lohman H. Occupational Therapists as Case Managers. Occupational therapy in health care. 1998; II(3): 65-77.

5. Liberty Life. Capital Disability and Impairment Benefit, 20I I. Retrieved from: http://www.liberty.co.za/Documents/capital-disability. pdf on 03 February 2016.

6. Adcorp Holdings. Adcorp's Index shows job losses, absenteeism costing the country. 20 I5. Retrieved from http://www.adcorp.co.za/ on 0I October 2015.

7. Buys T. Professional competencies in vocational rehabilitation: Results of a Delphi study. South African Journal of Occupational Therapy. 2015; 45(3): 48-54.

8. Baptiste S. Occupational therapy: The foundations, the changes, the future. Occupational therapy now. 20 I I: Volume I3. I: 3

9. Baum CM, Law M. Occupational therapy practice: Focusing on occupational performance. American Journal of Occupational Therapy. 1997; 5 I (4): 277-88.

10. Strasheim P, Buys T. Vocational rehabilitation under new constitutional, labour and equity legislation in a human rights culture: Future directions for South African occupational therapists. South African Journal of Occupational Therapy. 1996; 26(2): |4-28.

I I. Technical Assistance Guidelines of the Employment of People with Disabilities (TAG). Republic of South Africa Government Gazette. Department of Labour; 2002.

12. Case Management Society of America (CMSA). Standards of practice for case management, 20I0. Retrieved from: www.cmsa.org/ portals/0/pdf/memberonly/standardsofpractice on 0 I August 2015.

13. Case Manager Association of South Africa, 2013. Downloaded from http://www.casemanagement.co.za/ on 22 February 2015.

14. Fisher T. Roles and functions of a case manager. The American journal of occupational therapy. 1996; 50(6): 452.

15. Dufresne G. Statement: the occupational therapist as case manager. The American journal of occupational therapy. I99 I ; 45(I2): 1065-6.

16. Baldwin TM, Fisher T. Case management: entry-level practice for occupational therapists? The Case manager. 2005; I6(4): 47-5I. Retrieved from: http://dx.doi.org/10.1016/j.casemgr.2005.06.00I [Article] [PubMed] on 02 February 2016.

17. Miller J. International Literature Review: Approaches and Interventions for Sickness Benefit and Invalid's Benefit Clients. Ministry of Social Development, Wellington, 2006. Retrieved from: http://www. msd.govt.nz/about-msd-and-our-work/publications-resources/ literature-reviews/sbib/ on 12 November 2015.
18. Byrne LJ. The current and future role of occupational therapists in the South African group life insurance industry. South African Journal of Occupational Therapy. 2003; 33(2): 2-10.

19. Creswell. JW. Research Design: Qualitative, Quantitative, and Mixed Methods Approaches. 3rd edition. Sage Publications; 2009.

20. Sekaran U, Bougie R. Research Methods for Business: A skill building approach. John Wiley \& Sons; 2006.

21. Kgasi KM. The role of a case manager in a managed care organisation, 2010. Unpublished master's thesis. University of South Africa, Pretoria; 2010.

22. Golafshani, N. Understanding Reliability and Validity in Qualitative Research. The Qualitative Report. 2003; 8(4): 597-607. Downloaded from: http://www.nova.edu/sss/QR/QR8-4/golafshani.pdf.

23. Nulty DD. The adequacy of response rates to online and paper surveys: what can be done? Journal of Assessment \& Evaluation in Higher Education. 2008; 33(3): 30I-I4.

24. Braun V \& Clarke V. Using Thematic Analysis in Psychology. Qualitative Research in Psychology. 2006; 3: 77-I0I.

25. Anney, V. N. Ensuring the quality of the findings of qualitative research: looking at Trustworthiness Criteria. Journal of Emerging Trends in Educational Research and Policy Studies. 2014; 5(2): 272-281.

26. McDonald JH. Handbook of biological statistics. Baltimore: Sparky House Publishing MD; 2009.

27. Madrigal, D \& McClain B. Strengths and Weaknesses of Quantitative and Qualitative Research. Insights from Research; 2012. Downloaded from: http://www.uxmatters.com/mt/archives/2012/09/ strengths-and-weaknesses-of-quantitative-and-qualitative-research. php on 10 June 2016.

28. Kielhofner G. Research in occupational therapy: Methods of inquiry for enhancing practice. FA Davis; 2006.

29. Emsley R, Coetzer P. Disability claims on psychiatric grounds. South African Medical Journal. 1996; 86: 646.

30. Mokoka MT, Rataemane ST, Dos Santos M. Disability claims on psychiatric grounds in the South African context: A review. South African Journal of Psychiatry. 2012; I8(2): 34-4I.

31. Krupa T, Clark CC. Occupational therapists as case managers: Responding to current approaches to community mental health service delivery. Canadian Journal of Occupational Therapy. 1995; 62(I): 16-22.

Corresponding Author

Kreshnee Govender

kreshneeg@gmail.com 